\title{
Differences in vascular reactivity between pregnant women with chronic hypertension and preeclampsia
}

\author{
Toshitaka Mori, Kazushi Watanabe, Ai Iwasaki, Chiharu Kimura, Hiroshi Matsushita, Koichi Shinohara \\ and Akihiko Wakatsuki
}

The purpose of this study was to evaluate the distinct pathogenic mechanisms underlying chronic hypertension in pregnancy and preeclampsia in terms of oxidative stress and vascular reactivity. A total of 17 women with uncomplicated pregnancies, 30 women with preeclampsia and 17 women with chronic hypertension were evaluated. We measured serum derivatives of reactive oxygen metabolites (d-ROMs; marker of oxygen free radicals), flow-mediated vasodilation (FMD; marker of endothelial function) and intima-media thickness in the carotid artery (IMT; marker of atherogenesis) during pregnancy and 1 month after delivery. Serum d-ROM concentrations were significantly higher in women with chronic hypertension and severe preeclampsia than in the control group during pregnancy. d-ROM concentrations in all groups significantly decreased to similar levels 1 month after delivery. FMD was significantly lower during pregnancy in preeclamptic and chronic hypertension groups compared with the control group. FMD in preeclamptic groups significantly increased and normalized to control levels after delivery. Similarly, FMD in the chronic hypertension group significantly increased after delivery but was still lower. IMT in the chronic hypertension group was significantly higher than that in control and preeclamptic groups. These findings suggest that endothelial dysfunction induced by enhanced oxidative stress is reversible in women with preeclampsia, whereas impaired vascular reactivity may be associated with atherosclerotic changes in women with chronic hypertension.

Hypertension Research (2014) 37, 145-150; doi:10.1038/hr.2013.131; published online 26 September 2013

Keywords: chronic hypertension; endothelial dysfunction; intima-media thickness; oxidative stress; preeclampsia

\section{INTRODUCTION}

Preeclampsia is associated with the onset of hypertension and proteinuria after 20-week gestation and is a major cause of maternal, fetal and neonatal morbidity and mortality, affecting $\sim 4 \%$ of all pregnancies. ${ }^{1}$ Endothelial dysfunction has an important role in the pathogenesis of preeclampsia. ${ }^{2}$ The vascular endothelium regulates vascular smooth muscle tone by producing vasoconstrictors, such as endothelin-1 and thromboxane, and vasodilators, such as prostacyclin and nitric oxide. Oxidative stress may cause endothelial dysfunction, which may lead to hypertension due to reduced release of vasodilator agents such as nitric oxide, resulting in vasospasms. ${ }^{3,4}$ Several studies have revealed that free radicals increase the rate of maternal vascular malfunction in preeclampsia. ${ }^{5-9}$ Markers of lipid peroxidation are increased in the plasma and placenta of women with preeclampsia. ${ }^{10-12}$ We previously observed an increased production of oxygen free radicals without a decrease in antioxidant levels during pregnancy in women with preeclampsia. ${ }^{13}$ Oxygen free radicals may be generated from the placenta in women with preeclampsia, although its concentrations decrease after delivery. ${ }^{14,15}$

Flow-mediated vasodilation (FMD) in the brachial arteries assessed by high-resolution ultrasound is widely used to measure endothelial function. The technique provokes release of nitric oxide, resulting in vasodilation that can be quantitated as an index of vasomotor function. As reported in our previous study, FMD in brachial arteries decreased and correlated negatively with concentrations of oxygen free radicals in preeclamptic women, indicating that oxidative stress may impair endothelial function. We also demonstrated that enhanced oxidative stress and impaired vascular reactivity in preeclamptic women recovered to normal levels after delivery. ${ }^{13}$ Elevated blood pressure is accompanied by impaired vascular reactivity and an increase in diameter and intima-media thickness (IMT) of the carotid artery (a marker of atherogenesis) in patients with hypertension. Thus, increased IMT is considered a consequence of atherosclerotic diseases such as coronary artery disease. ${ }^{16,17}$ As chronic hypertension in pregnancy is associated with increased rates of severe maternal and fetal outcomes, and hypertension frequently persists after delivery and requires continuous medical treatment, ${ }^{18-20}$ the pathogenesis of chronic hypertension in pregnancy appears to differ from that of preeclampsia.

In the present study, we hypothesized that vascular reactivity, oxidative stress and atherosclerotic changes may contribute to the pathogenesis of chronic hypertension in pregnancy. To this end, we measured serum derivatives of reactive oxygen metabolites (d-ROMs), FMD in the brachial artery and IMT in the carotid artery in women 
with chronic hypertension during pregnancy and 1 month after delivery and compared these parameters with those in normal and preeclamptic women.

\section{METHODS}

\section{Study participants}

Between 1 April 2010 and 31 March 2012, we evaluated 30 women with preeclampsia, 11 women with chronic hypertension and 17 women with uncomplicated pregnancies, which were all singleton pregnancies. Blood pressure (BP) measurements were performed in the sitting position after 10 min rest. Enrollment criteria for preeclampsia included systolic BP above $140 \mathrm{~mm} \mathrm{Hg}$ or diastolic BP above $90 \mathrm{~mm} \mathrm{Hg}$ after 20 weeks' gestation and proteinuria above $300 \mathrm{mg}$ per $24 \mathrm{~h}$ without a urinary tract infection. Women with preeclampsia were classified as mild $(n=14$; systolic BP $\geqslant 140 \mathrm{~mm} \mathrm{Hg}$ and $<160 \mathrm{~mm} \mathrm{Hg}$ or diastolic BP $\geqslant 90 \mathrm{~mm} \mathrm{Hg}$ and $<110 \mathrm{~mm} \mathrm{Hg}$ and proteinuria $\geqslant 300 \mathrm{mg}$ and $<2 \mathrm{~g}$ per $24 \mathrm{~h})$ or severe $(n=16$; systolic BP $\geqslant 160 \mathrm{~mm} \mathrm{Hg}$ or diastolic BP $\geqslant 110 \mathrm{~mm} \mathrm{Hg}$ and proteinuria $\geqslant 2 \mathrm{~g}$ per $24 \mathrm{~h}$ ).

Chronic hypertension in pregnant women was defined as systolic BP above $140 \mathrm{~mm} \mathrm{Hg}$ or diastolic BP above $90 \mathrm{~mm} \mathrm{Hg}$ that was present prior to pregnancy. Women with unknown BP before pregnancy were diagnosed based on the presence of hypertension before 20 weeks' gestation. None of the preeclamptic participants presented with hemolysis, elevated liver enzymes or low platelet (HELLP) syndrome. A group of women with uncomplicated pregnancies matched for maternal and gestational age served as controls. Al women in the control group had a normal pregnancy and full-term delivery. Patients with any diseases, such as diabetes mellitus, gestational diabetes, coagulation disorders, thyroid disease and renal diseases, were excluded from participation. None of the participants smoked, used caffeine or alcohol, or were currently taking any medication known to influence lipoprotein metabolism and hypertension. All control women delivered by cesarean section before the onset of labor or previous cesarean section or breech presentation. All studies were conducted between 9000 and 1100 hours after a 12-h fast during pregnancy and 1 month after delivery. Each participant provided written informed consent, and the Ethics Committee of Aichi Medical University approved the study.

\section{Glucose, glycated hemoglobin and lipid concentrations}

Blood samples were collected from participants during pregnancy and 1 month after delivery. We determined plasma glucose and glycated hemoglobin by the hexokinase technique and HPLC, respectively. The levels of total cholesterol, high-density lipoprotein (HDL), low-density lipoprotein (LDL) and total triglyceride in the plasma were measured enzymatically. ${ }^{21}$

\section{Derivatives of reactive oxygen metabolites}

Blood samples were collected from participants during pregnancy and 1 month after delivery. Serum d-ROMs were analyzed using the Free Radical Analytical System (FRAS) 4 (Diacron, Parma, Italy), which measures serum levels of organic hydroperoxides that are indicative of the levels of free radicals they originated from..$^{22-24}$ In an acidic buffer, hydroperoxides react with transition metal ions liberated from proteins and are converted to alkoxyl and peroxyl radicals that can oxidize an additive (N, N-diethyl-para-phenylenediamine) to the corresponding radical cation species. The concentration of this persisten species was determined using spectrophotometry $(505 \mathrm{~nm})$. d-ROM results are expressed as Carratelli units (CARR U) by the name of the Italian research chemist Mauro Carratelli: 1 CARR U corresponds to $0.08 \mathrm{mg}$ per $100 \mathrm{ml} \mathrm{H}_{2} \mathrm{O}_{2}$.

\section{Endothelial function}

Endothelial function was measured using FMD in the brachial artery assessed by high-resolution ultrasound. As several factors affect the magnitude of FMD, including diet, time and medication, the measurement conditions should be consistent. Patients rested in a supine position with a $30^{\circ}$ tilt for $10 \mathrm{~min}$ prior to measuring vasodilatory responses using high-resolution Doppler ultrasonography equipment (VolusonE8, GE Healthcare, Zipf, Austria) with a $10-\mathrm{MHz}$ transducer to image the right brachial artery. The brachial artery was selected because it is easily accessible using ultrasound. A non-tortuous segment of the brachial artery was scanned longitudinally $4-5 \mathrm{~cm}$ above the antecubital fossa to obtain a clear image. After the transducer position was determined, the skin was marked and the arm was maintained in the same position throughout the study. After obtaining baseline images of the brachial artery and determining arterial flow velocity, a BP cuff encircling the proximal portion of the arm was inflated to $250 \mathrm{~mm} \mathrm{Hg}$ for $5 \mathrm{~min}$ and suddenly deflated. Increased blood flow after sudden cuff deflation, or reactive hyperemia, results in FMD. Arterial flow velocity was determined and the brachial artery was imaged $1 \mathrm{~min}$ after cuff deflation. BP and heart rate were monitored and recorded throughout the investigation. The brachial artery diameter was measured from the anterior and posterior walls of the media-adventitia interface (' $m$ ' line) at the end of diastole identified by the onset of the R-wave. Four cardiac cycles were analyzed for each scan and averaged. Vessel diameters were measured without knowledge of participant information. FMD was calculated as the percent increase in arterial diameter during hyperemia and used as an index of endothelium-dependent vasodilation. ${ }^{25,26}$ In our laboratory, intraobserver and interobserver variability for repeat measurements were $0.03 \pm 0.02$ and $0.05 \pm 0.03 \mathrm{~mm}$, respectively. The variability for FMDs performed on two separate days was $2.1 \pm 0.9 \%$.

\section{Intima-media thickness}

Ultrasound is widely used to assess IMT, wall thickness in carotid arteries, aging and hypertension. IMT was defined as thickness of the tunica intima and the tunica media. As the adventitia cannot be distinguished from surrounding structures, measurement of IMT is necessary to assess the two innermost layers of the arterial wall. ${ }^{27}$ Participants were examined supine with the head rotated $45^{\circ}$ towards the left side. Images of the common carotid artery were centered $15 \mathrm{~mm}$ below the bulb. IMT was measured in the distal straight portion of the right common carotid artery using high-resolution Doppler ultrasonography equipment (VolusonE8, GE Healthcare) with a $10-\mathrm{MHz}$ linear-array transducer.

\section{Statistical analyses}

SPSS Statistical Software version 14.0 for Windows (SPSS Inc., Chicago, IL, USA) was used for statistical analyses. Data are expressed as mean \pm standard deviation (s.d.). Patient characteristics, serum d-ROM concentrations, FMD and IMT were compared using one-way analysis of variance followed by Scheffe's multiple comparisons. We analyzed differences in patient characteristics, d-ROM concentrations and FMD during pregnancy and 1 month after delivery using Student's unpaired $t$-test when there was a normal distribution or using the Mann-Whitney test when the parameters were not normally distrbuted. $P<0.05$ was considered statistically significant

\section{RESULTS}

Maternal and gestational age and body mass index were not significantly different between the mild and severe preeclamptic groups, chronic hypertension group and the control group. Plasma hematocrit, creatinine and uric acid levels during pregnancy were significantly elevated in the severe preeclamptic group compared with the other groups (Table 1).

The severe preeclamptic participants had significantly higher levels of plasma triglyceride and LDL levels; however, the levels of other lipids did not differ significantly among four groups. Plasma concentrations of blood glucose and glycated hemoglobin did not differ among the four groups (Table 2).

Systolic and diastolic BPs during pregnancy were significantly elevated in the mild and severe preeclamptic and chronic hypertension groups compared with the control group. The systolic and diastolic BPs 1 month after delivery was significantly decreased in both of the preeclamptic groups but not in the chronic hypertension group. There were no significant differences in the baseline brachial artery diameter and blood flow between any of the four groups during pregnancy and 1 month after delivery (Table 3). 
Table 1 Subject characteristics

\begin{tabular}{|c|c|c|c|c|c|c|c|c|}
\hline & \multicolumn{2}{|c|}{ Normal $(\mathrm{n}=17)$} & \multicolumn{2}{|c|}{ Mild preeclampsia $(n=14)$} & \multicolumn{2}{|c|}{ Severe preeclampsia $(n=16)$} & \multicolumn{2}{|c|}{ Chronic hypertension $(\mathrm{n}=17)$} \\
\hline & $\begin{array}{c}\text { During } \\
\text { Pregnancy }\end{array}$ & $\begin{array}{c}1 \text { Month after } \\
\text { delivery }\end{array}$ & $\begin{array}{c}\text { During } \\
\text { pregnancy }\end{array}$ & $\begin{array}{c}1 \text { Month after } \\
\text { delivery }\end{array}$ & $\begin{array}{c}\text { During } \\
\text { pregnancy }\end{array}$ & $\begin{array}{c}1 \text { Month after } \\
\text { delivery }\end{array}$ & $\begin{array}{c}\text { During } \\
\text { pregnancy }\end{array}$ & $\begin{array}{c}1 \text { Month } \\
\text { after delivery }\end{array}$ \\
\hline Age (years) & $32.8 \pm 5.0$ & - & $33.5 \pm 3.8$ & - & $31.0 \pm 4.9$ & - & $34.4 \pm 5.3$ & - \\
\hline Gestational age at test (weeks) & $34.5 \pm 4.9$ & - & $34.3 \pm 4.2$ & - & $33.7 \pm 2.4$ & - & $34.1 \pm 3.3$ & - \\
\hline Parity & $1.9 \pm 1.1$ & & $1.7 \pm 0.9$ & & $1.6 \pm 1.4$ & & $1.7 \pm 0.8$ & \\
\hline BMI before pregnancy $\left(\mathrm{kg} \mathrm{m}^{-2}\right)$ & $19.6 \pm 2.1$ & - & $24.3 \pm 7.3$ & - & $21.3 \pm 3.7$ & - & $24.7 \pm 6.8$ & - \\
\hline Hematocrit (\%) & $29.3 \pm 8.3$ & $39.2 \pm 2.0 \mathrm{~g}$ & $31.5 \pm 2.5$ & $34.8 \pm 2.3^{a, g}$ & $37.8 \pm 3.6^{a, d}$ & $36.0 \pm 2.1^{\mathrm{b}}$ & $33.7 \pm 4.1$ & $40.2 \pm 2.7^{c, e, h}$ \\
\hline Platelet $\left(\times 10^{4}\right)$ & $22.2 \pm 4.6$ & $27.5 \pm 10.1^{\mathrm{h}}$ & $25.0 \pm 8.2^{\mathrm{a}}$ & $28.4 \pm 8.8$ & $21.2 \pm 5.2$ & $33.2 \pm 11.4^{\mathrm{h}}$ & $24.1 \pm 6.4$ & $24.9 \pm 4.8$ \\
\hline AST $\left(\mid U^{-1}\right)$ & $16.0 \pm 3.9$ & $22.4 \pm 7.4$ & $13.6 \pm 4.1$ & $18.0 \pm 7.5$ & $22.6 \pm 5.9^{b, c}$ & $19.8 \pm 5.3$ & $14.0 \pm 6.2^{f}$ & $26.0 \pm 6.9$ \\
\hline $\operatorname{ALT}\left(|\cup|^{-1}\right)$ & $9.2 \pm 2.0$ & $15.1 \pm 2.4^{\mathrm{h}}$ & $8.8 \pm 5.2$ & $15.6 \pm 7.6$ & $18.8 \pm 12.9^{a, d}$ & $20.5 \pm 9.3$ & $8.3 \pm 2.5^{f}$ & $26.0 \pm 3.4^{b, d, h}$ \\
\hline $\mathrm{BUN}\left(\mathrm{mgdl}{ }^{-1}\right)$ & $7.9 \pm 2.8$ & $11.6 \pm 4.4$ & $8.2 \pm 3.5$ & $11.3 \pm 1.7$ & $12.2 .1 \pm 2.7^{b, d}$ & $9.6 \pm 2.9^{h}$ & $7.5 \pm 0.5$ & $8.8 \pm 2.0^{f}$ \\
\hline Creatinine $\left(\mathrm{mg} \mathrm{dl}^{-1}\right)$ & $0.44 \pm 0.07$ & $0.52 \pm 0.09$ & $0.50 \pm 0.09$ & $0.55 \pm 0.06$ & $0.61 \pm 0.16^{a}$ & $0.57 \pm 0.11$ & $0.46 \pm 0.08^{e}$ & $0.60 \pm 0.11$ \\
\hline Uric acid (mgdl-1) & $4.0 \pm 0.8$ & $4.4 \pm 06$ & $5.0 \pm 1.3$ & $5.3 \pm 0.9$ & $6.2 \pm 1.4^{\mathrm{a}}$ & $5.9 \pm 0.6^{a}$ & $4.8 \pm 1.0^{f}$ & $5.8 \pm 1.1^{b}$ \\
\hline
\end{tabular}

Abbreviations: ALT, alanine aminotransferase; AST, asparate aminotransferase; BMI, body mass index; BUN, blood urea nitrogen,

Data are expressed as mean \pm s.d.

a $P<0.01$, b $P<0.05$ as compared with normal

${ }^{c} P<0.01,{ }^{d} P<0.05$ as compared with mild preeclampsia,

${ }^{\mathrm{e}} P<0.01,{ }^{\mathrm{f}} P<0.05$ as compared with severe preeclampsia,

$\mathrm{g} P<0.01,{ }^{\mathrm{h}} P<0.05$ as compared with during pregnancy.

Table 2 Serum glucose and lipids

\begin{tabular}{|c|c|c|c|c|c|c|c|c|}
\hline & \multicolumn{2}{|c|}{ Normal } & \multicolumn{2}{|c|}{ Mild preeclampsia } & \multicolumn{2}{|c|}{ Severe preeclampsia } & \multicolumn{2}{|c|}{ Chronic hypertension } \\
\hline & $\begin{array}{c}\text { During } \\
\text { pregnancy }\end{array}$ & $\begin{array}{c}1 \text { Month after } \\
\text { delivery }\end{array}$ & $\begin{array}{l}\text { During pr } \\
\text { egnancy }\end{array}$ & $\begin{array}{c}1 \text { Month after } \\
\text { delivery }\end{array}$ & $\begin{array}{c}\text { During } \\
\text { pregnancy }\end{array}$ & $\begin{array}{c}1 \text { Month after } \\
\text { delivery }\end{array}$ & $\begin{array}{c}\text { During } \\
\text { pregnancy }\end{array}$ & $\begin{array}{c}1 \text { Month after } \\
\text { delivery }\end{array}$ \\
\hline Fasting blood sugar $\left(\mathrm{mg} \mathrm{dl}^{-1}\right)$ & $79.7 \pm 7.3$ & - & $80.5 \pm 8.3$ & - & $79.4 \pm 10.5$ & - & $82.3 \pm 6.2$ & - \\
\hline Glycated hemoglobin (\%) & $4.8 \pm 0.2$ & - & $5.0 \pm 0.2$ & - & $4.9 \pm 0.2$ & - & $5.1 \pm 0.2$ & - \\
\hline Total cholesterol $\left(\mathrm{mg} \mathrm{dl}^{-1}\right)$ & $236 \pm 53$ & $220 \pm 37$ & $240 \pm 35$ & $210 \pm 27^{d}$ & $269 \pm 43$ & $237 \pm 46^{c}$ & $242 \pm 41$ & $216 \pm 33^{d}$ \\
\hline HDL cholesterol (mg dl $\left.{ }^{-1}\right)$ & $73 \pm 11$ & $79 \pm 15$ & $73 \pm 13$ & $70 \pm 15$ & $83 \pm 23$ & $66 \pm 14^{\mathrm{b}, \mathrm{c}}$ & $71 \pm 20$ & $66 \pm 17$ \\
\hline LDL cholesterol (mg dl $\left.{ }^{-1}\right)$ & $106 \pm 32$ & $115 \pm 35$ & $141 \pm 38$ & $131 \pm 18$ & $163 \pm 44^{a}$ & $148 \pm 39^{b}$ & $124 \pm 37$ & $136 \pm 26$ \\
\hline
\end{tabular}

Abbreviations: HDL, high-density lipoprotein; LDL, low-density lipoprotein,

Data are expressed as mean $\pm \mathrm{s}$.d.

Data are expressed as mean \pm s.d.
${ }^{a} P<0.01,{ }^{b} P<0.05$ as compared with normal,

${ }^{\mathrm{c}} P<0.01,{ }^{\mathrm{d}} P<0.05$ as compared with during pregnancy.

Table 3 Blood pressure, heart rate, artery diameter, blood flow

\begin{tabular}{|c|c|c|c|c|c|c|c|c|}
\hline & \multicolumn{2}{|c|}{ Normal } & \multicolumn{2}{|c|}{ Mild preeclampsia } & \multicolumn{2}{|c|}{ Severe preeclampsia } & \multicolumn{2}{|c|}{ Chronic hypertension } \\
\hline & $\begin{array}{c}\text { During } \\
\text { pregnancy }\end{array}$ & $\begin{array}{c}1 \text { Month after } \\
\text { delivery }\end{array}$ & $\begin{array}{c}\text { During } \\
\text { pregnancy }\end{array}$ & $\begin{array}{c}1 \text { Month after } \\
\text { delivery }\end{array}$ & $\begin{array}{c}\text { During } \\
\text { pregnancy }\end{array}$ & $\begin{array}{c}1 \text { Month after } \\
\text { delivery }\end{array}$ & $\begin{array}{c}\text { During } \\
\text { pregnancy }\end{array}$ & $\begin{array}{c}1 \text { Month after } \\
\text { delivery }\end{array}$ \\
\hline Systolic BP (mmHg) & $116.6 \pm 11.9$ & $111.9 \pm 10.6$ & $144.7 \pm 7.8^{a}$ & $126.8 \pm 10.7^{h, b}$ & $161.3 \pm 21.4^{a, c}$ & $128.1 \pm 8.7^{g, b}$ & $148.2 \pm 6.8^{a}$ & $140.7 \pm 17.4^{a, d, f}$ \\
\hline Diastolic BP (mmHg) & $72.9 .6 \pm 7.1$ & $71.0 \pm 9.5$ & $85.4 \pm 12.1^{\mathrm{a}}$ & $76.0 \pm 9.6$ & $101.0 \pm 1.4^{b}$ & $80.2 \pm 6.4^{b, d}$ & $87.1 \pm 5.7^{\mathrm{a}, \mathrm{e}}$ & $85.5 \pm 11.0^{\mathrm{a}, \mathrm{f}}$ \\
\hline Heart rate (beats $\min ^{-1}$ ) & $77.8 \pm 6.9$ & $74.5 \pm 8.5$ & $74.4 \pm 10.1$ & $79.4 \pm 12.3$ & $77.5 \pm 9.9$ & $76.5 \pm 6.6$ & $79.0 \pm 6.0$ & $79.1 \pm 4.4$ \\
\hline Baseline diameter (mm) & $3.4 \pm 0.4$ & $3.1 \pm 0.3$ & $3.5 \pm 0.4$ & $3.0 \pm 0.2$ & $3.5 \pm 0.2$ & $3.2 \pm 0.2$ & $3.7 \pm 0.2$ & $3.2 \pm 0.2$ \\
\hline Baseline flow $\left(\mathrm{ml} \mathrm{min}^{-1}\right)$ & $204 \pm 79$ & $119 \pm 43^{h}$ & $227 \pm 61$ & $122 \pm 68^{h}$ & $201 \pm 118$ & $137 \pm 52$ & $224 \pm 118$ & $171 \pm 55$ \\
\hline Hyperemic flow $\left(\mathrm{ml} \mathrm{min}^{-1}\right)$ & $389 \pm 169$ & $288 \pm 146$ & $447 \pm 161$ & $336 \pm 105$ & $376 \pm 102$ & $393 \pm 92$ & $423 \pm 37$ & $303 \pm 114$ \\
\hline
\end{tabular}

Abbreviations: BP, blood pressure. Data are expressed as mean \pm s.d.

a $P<0.01$, b $P<0.05$ as compared with normal,

${ }^{c} P<0.01,{ }^{d} P<0.05$ as compared with mild preeclampsia,

e $P<0.01$, f $P<0.05$ as compared with severe preeclampsia,

$\mathrm{g} P<0.01,{ }^{h} P<0.05$ as compared with during pregnancy. 
During pregnancy, women in the severe preeclamptic (716.5 $\pm 270.1 \mathrm{CARR} U, \quad P<0.05)$ and chronic hypertension (722.8 \pm 140.6 CARR $U, P<0.05)$ groups had significantly higher plasma d-ROM concentrations compared with the control group (565.5 \pm 122.9 CARR U). d-ROM concentrations in both preeclamptic groups, the chronic hypertension group and the control group were significantly decreased 1 month after delivery. Concentrations 1 month after delivery did not significantly differ between the groups (Figure 1).

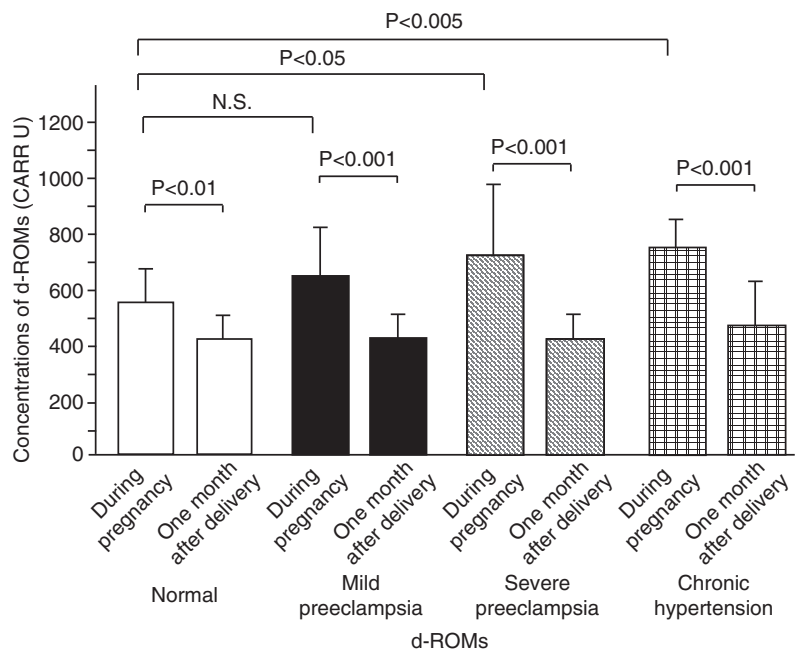

Figure 1 Concentrations of d-ROMs in maternal blood during pregnancy and 1 month after delivery in the control group, both preeclamptic women and pregnant women with chronic hypertension. Open, closed, diagonally hatched and checkered columns represent women with uncomplicated pregnancies, mild preeclamptic women, severe preeclamptic women and women with chronic hypertension, respectively. N.S. indicates not significant. Data are expressed as mean \pm s.d.

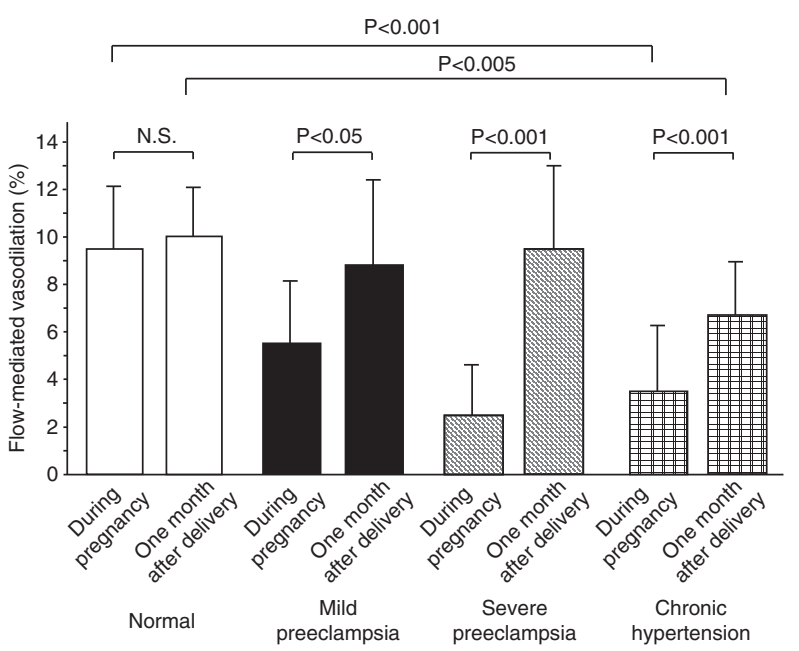

Figure 2 FMD during pregnancy and 1 month after delivery in the control group, both preeclamptic women and pregnant women with chronic hypertension. Open, closed, and diagonally hatched and checkered columns represent women with uncomplicated pregnancies, mild preeclamptic women, severe preeclamptic women and women with chronic hypertension, respectively. N.S. indicates not significant. Data are expressed as mean \pm s.d.
FMD during pregnancy was significantly decreased in both preeclamptic groups (mild, 5.6 $\pm 2.5 \%, P<0.001$; severe, $2.6 \pm 2.2 \%$, $P<0.001)$ and the chronic hypertension group $(3.6 \pm 2.3 \%, P<0.001)$ compared with the control group $(9.3 \pm 2.9 \%)$. FMD in both preeclamptic groups was increased 1 month after delivery, and it was not significantly different from the controls. Although FMD in the chronic hypertension group 1 month after delivery was increased, it was significantly lower than the other groups (Figure 2). FMD was negatively correlated with $\mathrm{d}$-ROM concentrations in preeclamptic women $(r=-0.472, P<0.05)$. No correlation was observed in the chronic hypertension group (Figures $3 \mathrm{a}$ and $\mathrm{b}$ ).

IMT in the chronic hypertension group $(0.50 \pm 0.08 \mathrm{~mm})$ was significantly higher than the other groups (controls, $0.25 \pm 0.05 \mathrm{~mm}$, $P<0.001$; mild, $0.30 \pm 0.06 \mathrm{~mm}, P<0.001$; severe, $0.31 \pm 0.07 \mathrm{~mm}$, $P<0.001)$. There was no difference between both preeclampsia groups and the controls (Figure 4).

\section{DISCUSSION}

In the present study, serum d-ROM concentrations increased during pregnancy, and decreased after delivery in women with preeclampsia and chronic hypertension. These results indicate that, whereas oxidative stress increased during pregnancy, it normalized after delivery in both groups, consistent with our previous report. ${ }^{13} \mathrm{We}$ speculate that increased oxygen free radicals may originate from the placenta in preeclamptic women because their levels tended to decrease 5 days after delivery of the placenta. ${ }^{28}$ Wang et al. ${ }^{29}$ also demonstrated that placental mitochondria contribute to the abnormal increase in lipid peroxidation that occurs in the preeclamptic placenta by both an increase in their numbers and susceptibility to oxidation.Thus, mitochondrial generation of superoxide could be an important source of oxidative stress in preeclampsia.

Similar to our previous findings, ${ }^{13}$ FMD decreased during pregnancy and normalized after delivery in preeclamptic women in this study. FMD in pregnant women with chronic hypertension also decreased during pregnancy and increased after delivery but did not return to normal levels. FMD correlated negatively with d-ROM concentrations in preeclamptic women but not in pregnant women with chronic hypertension. These results suggest that, although enhanced oxidative stress may be associated with impaired vascular reactivity in patients with preeclampsia, factors other than oxidative stress may adversely affect endothelial function in patients with chronic hypertension.

IMT has been used as a clinical marker of atherogenesis, and a number of studies have reported increased IMT in patients with atherosclerotic diseases such as myocardial infarction and stroke. ${ }^{30,31}$ Pregnant women with chronic hypertension had significantly greater IMT compared with preeclamptic and normotensive pregnant women in our study. As elevated BP impairs the vascular endothelium, hypertension may also be associated with endothelial dysfunction in women with preeclampsia and chronic hypertension. Given that prolonged exposure to high BP can cause atherosclerotic changes in the vessel wall, IMT was greater in women with chronic hypertension compared with women with preeclampsia. Several studies have shown that a carotid arterial IMT $>1.0 \mathrm{~mm}$ is associated with an increased risk of coronary events. In the present study, however, IMT was $<1.0 \mathrm{~mm}$ in women with chronic hypertension. As endogenous estrogen can protect against atherosclerotic changes, premenopausal women may be at less risk of cardiovascular diseases than postmenopausal women. We speculate that vascular changes in pregnant women with chronic hypertension may represent a preatherogenic state, which can become pathogenic after menopause. 

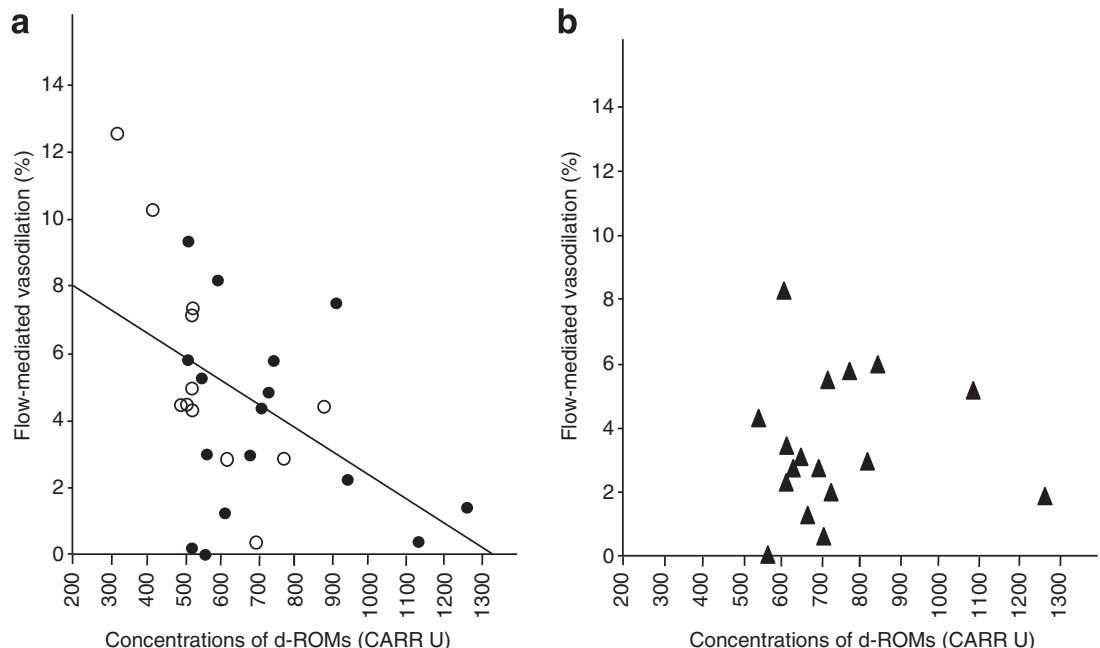

Figure 3 (a) Relationship between concentrations of d-ROMs and FMD during pregnancy in preeclamptic women. Open circles and closed circles represent mild preeclamptic women and severe preeclamptic women, respectively. $(r=-0.472, P<0.05)$. (b) Relationship between concentrations of $d-R O M s$ and FMD during pregnancy in women with chronic hypertension. Triangles represent women with chronic hypertension $(r=0.058, P=0.826)$.

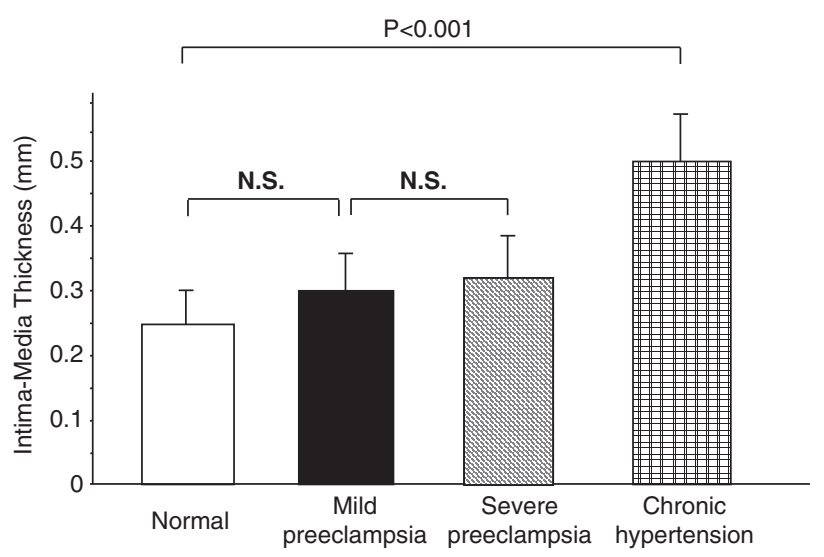

Figure 4 IMT during pregnancy in the control group, both preeclamptic women and pregnant women with chronic hypertension. Open, closed, and diagonally hatched and checkered columns represent women with uncomplicated pregnancies, mild preeclamptic women, severe preeclamptic women and women with chronic hypertension, respectively. N.S. indicates not significant. Data are expressed as mean \pm s.d.

Many studies have suggested that women with a history of preeclampsia are at an increased risk of developing cardiovascular diseases later in life. ${ }^{32-34}$ Hammad et al. ${ }^{35}$ found that women with a history of preeclampsia had a lower FMD and higher BP compared with women without a history of preeclampsia 1 year after the pregnancy. Lampinen et al. ${ }^{36}$ reported that vasodilation was impaired 5-6 years after pregnancy in women with prior preeclampsia. In this study, endothelial dysfunction in women with preeclampsia improved soon after delivery. Several factors, such as insulin resistance, inflammation and oxidative stress, may adversely affect cardiovascular risk in women with a history of preeclampsia. However, vascular failure in chronic hypertension may differ from that in preeclampsia, as evidenced by the fact that the associated endothelial dysfunction did not normalize after delivery. Women with chronic hypertension in pregnancy may also be at high risk of developing cardiovascular diseases later in life. Indeed, elevated BP may be inherent prior to pregnancy and persistent after delivery, leading to prolonged high BP. This suggests that factors other than oxidative stress may contribute to endothelial dysfunction in chronic hypertension. Further research will be needed to address these issues.

1 Mackay AP, Berg CJ, Atrash HK. Pregnancy-related mortality from preeclampsia and eclampsia. Obstet Gynecol 2001; 97: 533-538.

2 Mori T, Shinohara K, Wakatsuki A, Watanabe K, Fujimaki A. Adipocytokines and endothelial function in preeclamptic women. Hyperten Res 2010; 33: 250-254.

3 Watanabe K, Okatani Y, Sagara Y. Potentiating effect of hydrogen peroxide on the serotonin-induced vasocontraction in human umbilical artery. Acta obstet Gynecol Scand 1996; 75: 783-789.

4 Okatani Y, Watanabe K, Sagara Y. Effect of nitric oxide, prostacyclin, and thromboxane on the vasospastic action of hydrogen peroxide on human umbilical artery. Acta obstet Gynecol Scand 1997; 76: 515-520.

5 Watanabe K, Mori T, Iwasaki A, Kimura C, Matsushita H, Shinohara K, Wakatsuki A. Increased oxidant generation in the metabolism of hypoxanthine to uric acid and endothelial dysfunction in early-onset and late-onset preeclamptic women. J Matern Fetal Neonatal Med 2012; 25: 2662-2666.

6 Bdolah Y, Karumanchi SA, Sachs BP. Recent advances in understanding of preeclampsia. Croat Med J 2005; 46: 728-736.

7 Chappell LC, Seed PT, Briley AL, Kelly FJ, Lee R, Hunt BJ, Parmar K, Bewley SJ, Shennan AH, Steer PJ, Poston L. Effect of antioxidants on the occurrence of preeclampsia in women at increased risk: a randomized trial. Lancet 1999; 354: 810-816.

8 Raijmakers MTM, Dechend R, Poston L. Oxidative stress and preeclampsia: rationale for antioxidant clinical trials. Hypertension 2004; 44: 374-380.

9 Hubel CA. Oxidative stress in the pathogenesis of preeclampsia. Exp Biol Med 1999; 222: 222-235.

10 Redman CWG, Sargent IL. Placental stress and pre-eclampsia: a revised view. Placenta 2009; 23: S38-S42.

11 Gupta S, Agarwal A, Sharma RK. The role of placental oxidative stress and lipid peroxidation in preeclampsia. Obstet Gynecol Surv 2005; 60: 807-816.

12 Beguml R. Lipid peroxidation and antioxidant status in preeclampsia. J Enam Med Col 2011; 1: 56-59.

13 Watanabe K, Mori T, Wakatsuki A, Kimura C, Iwasaki A. Increased oxygen free radical production during pregnancy may impair vascular reactivity in preeclamptic women. Hyperten Res 2013; 36: 356-360.

14 Fujimaki A, Watanabe K, Mori T, Kimura C, Shinohara K, Wakatsuki A. Placental oxidative DNA damage and its repair in preeclamptic women with fetal growth restriction. Placenta 2011; 32: 367-372.

15 Kimura C, Watanabe K, Iwasaki A, Mori T, Matsushita H, Shinohara K, Wakatsuki A. The severity of hypoxic changes and oxidative DNA damage in the placenta of early- 
onset preeclamptic women and fetal growth restriction. J Matern Fetal Neonatal Med 2012; 26: 491-496.

16 Matthias WL, Hugh SM, Michiel LB. Prediction of clinical cardiovascular events with carotid intima-media thickness. a systematic review and meta-analysis. Circulation 2007; 115: 459-467.

17 Pierluigi C, Pasquale PF, Enrico V. Does carotid intima-media thickness regression predict reduction of cardiovascular events? A meta-analysis of 41 randomized trials. J Am Coll Cardiol 2010; 56: 2006-2020.

18 Sibai BM. Chronic hypertension in pregnancy. Obstet Gynecol 2002; 100 369-377.

19 Panza JA, Casno PR, Kilcoyne CM, Quyyumi AA. Role of endothelium-derived nitric oxide in the abnormal endothelium-dependent vascular relaxation of patients with essential hypertension. Circulation 1993; 87: 1468-1474.

20 Chappell LC, Enye S, Seed P, Briley AL, Poston L, Shennan AH. Adverse perinatal outcomes and risk factors for preeclampsia in women with chronic hypertension: a prospective study. Hypertension 2008; 51: 1002-1009.

21 Allain CC, Poon LS, Chan CS, Richmond W, Fu PC. Enzymatic determination of total serum cholesterol. Clin Chem 1974; 20: 470-475.

22 Trotti R, Carratelli M, Barbieri M. Performance and clinical application of a new, fast method for the detection of hydroperoxides in serum. Panminerva Med 2002; 44: $37-40$.

23 Parmigiani S, Payer C, Massari A, Bussolati G, Bevilacqua G. Normal values of reactive oxygen metabolites on the cord-blood of fullterm infants with a colorimetric method. Acta Biomed Ateneo Parmense 2000; 71: 59-64.

24 Cesarone MR, Belcaro G, Carratelli M, Cornelli U, De Sanctis MT, Incandela I, Barsotti A, Terranova R, Nicolaides A. A simple test to monitor oxidative stress. Int Angiol 1998; 18: 127-130.

25 Rubanyi GM, Romero JC, Vanhoutte PM. Flow-induced release of endothelium-derived relaxing factor. Am J Physiol 1986; 250: H1145-H1149.

26 Corretti MC, Anderson TJ, Benjamin EJ, Celermajer D, Charbonneau F, Creager MA Deanfield J, Drexler H, Gerhard-Herman M, Herrington D, Vallance P, Vita J, Vogel R.
Guidelines for the ultrasound assessment of endothelial-dependent flow-mediated vasodilation of the brachial artery. J Am Coll Cardiol 2002; 39: 257-265.

27 Boutouyrie P, Laurent S, Girerd X. Common carotid artery stiffness and patterns of left ventricular hypertrophy in hypertensive patients. Hypertension 1995; 25: 651-659.

28 Watanabe K, Iwasaki A, Mori T, Kimura C, Matsushita H, Shinohara K, Wakatsuki A Differences in levels of oxidative stress in mothers and neonate: the impact of mode of delivery. J Matern Fetal Neonatal Med 2013 (in press).

29 Wang Y, Walsh SW. Placental mitochondria as a source of oxidative stress in preeclampsia. Placenta 1998; 19: 581-586.

30 Simon A, Gariepy J, Chironi G, Megnien JL, Levenson J. Intima-media thickness: a new tool for diagnosis and treatment of cardiovascular risk. J Hypertens 2002; 20 159-169.

31 Celermajer DS, Sorensen KE, Bull C, Robinson J, Deanfield JE. Endotheliumdependent dilation in the systemic arteries of asymptomatic subjects relates to coronary risk factors and their interaction. J Am Coll Cardiol 1994; 24: 1468-1474.

32 Fraser A, Nelson SM, Macdonald-Wallis C, Cherry L, Butler E, Sattar N, Lawlor DA Associations of pregnancy complications with calculated cardiovascular disease risk and cardiovascular risk factors in middle age: the Avon longitudinal study of parents and children. Circulation 2012; 125: 1367-1380.

33 Germain AM, Romanik MC, Guerra I, Solari S, Reyes MS, Johnson RJ, Price K, Karumanchi SA, Valdés G. Endothelial dysfunction a link among preeclampsia, recurrent pregnancy loss, and future cardiovascular events? Hypertension 2007; 49: 90-95.

34 Yinon Y, Kingdom JCP, Odutayo A, Moineddin R, Drewlo S, Lai V, Cherney DZ, Hladunewich MA. Vascular dysfunction in women with a history of preeclampsia and intrauterine growth restriction: Insights into future vascular risk. Circulation 2010; 122: $1846-1853$

35 Hamad RR, Eriksson MJ, Silveira A, Hamsten A, Bremme K. Decreased flow-mediated dilation is present 1 year after a pre-eclamptic pregnancy. J Hypertens 2007; 25: 2301-2307.

36 Lampinen KH, Ronnback M, Kaaja RJ, Groop PH. Impaired vascular dilatation in women with a history of pre-eclampsia. J Hypertens 2006; 24: 751-756. 